\title{
Observation of Substructure in Steels and Ni200 Using Electron-Channeling Contrast Imaging
}

James H. Steele Jr.

Consultant, 2019 Nova Road, Pine CO 80470

The application of electron -channeling contrast imaging[1] to observe recovered substructure in hot rolled Ni200 and 2205 duplex stainless steel, and dislocation cell structure in cold drawn IF steel is described in this paper. A 4 -crystal backscatter electron(BSE) detector was used to record channeling contrast images from samples, which were ground and polished via standard metallographic methods, and finished by electropolishing. The Ni200 samples were part of a study of recrystallization after hot rolling[2]. The 2205 duplex stainless steel was examined after being hot rolled in a laboratory mill.

A BSE image of a partially recrystallized Ni200 sample is presented in Figure 1. Contrast between the recrystallized grains, as well as recovered sub -grains is a result of electron -channeling wherein intensity of the BSE signal varies with orientation of the crystal lattice. The micrograph shows recrystallized grains that have formed in layers along prior grain boundaries, and recovered subgrains, which exhibit a $2-5$ micron cell size. Microhardness measurements on the recovered substructure showed a kno op hardness of $150-180$, while the recrystallized grains exhibited a hardness of $55-65$. Figure 2 provides a higher magnification image, which shows individual recovered subgrains more clearly, and some intermediate regions that appear to be forming a fully recrystallized grain.

Figure 3 and 4 provide BSE images from a 2205 duplex stainless steel sample after hot rolling with a $75 \%$ thickness reduction and a finishing temperature of $900^{\circ} \mathrm{C}$. Alternating layers of ferrite (bcc) and austenite (fcc) can be obs erved in Figure 3, after electrolytic etching, which attacks the ferrite phase more rapidly then the austenite. The austenite layer shows a tendency for recovered subgrains, while the ferrite layer shows a fine recrystallized grain structure. Figure 4 shows an electropolished sample of the same layered mixture without the topographic contrast from the steps at the phase boundaries.

Figures 5 and 6 show the dislocation cell structure generated during cold drawing of an interstitial free, drawing quality, low carbon steel[3]. The sidewall of the cup was electropolished to provide the image shown in Figure 5, which shows a dislocation cell size of approximately 1 micron. The deformation in the sidewall was estimated to be about 70 to $80 \%$ in the drawing direction, which is horizontal in the micrograph. Figure 6 shows the cell structure developed in the bottom of the cup, which undergoes a biaxial stretching of only about $10-15 \%$.

\section{References}

[1] Oliver C. Wells, Scanning Electron Microscopy, McGraw Hill, New York (1974) 160.

[2] I. Weiss, Engineering Foundation Grant, Report RI-A-82-5 (1982).

[3] J.H. Steele Jr. and D.F. Lentz, Fractography in Failure Analysis ASTM STP 645 (1978) 5. 

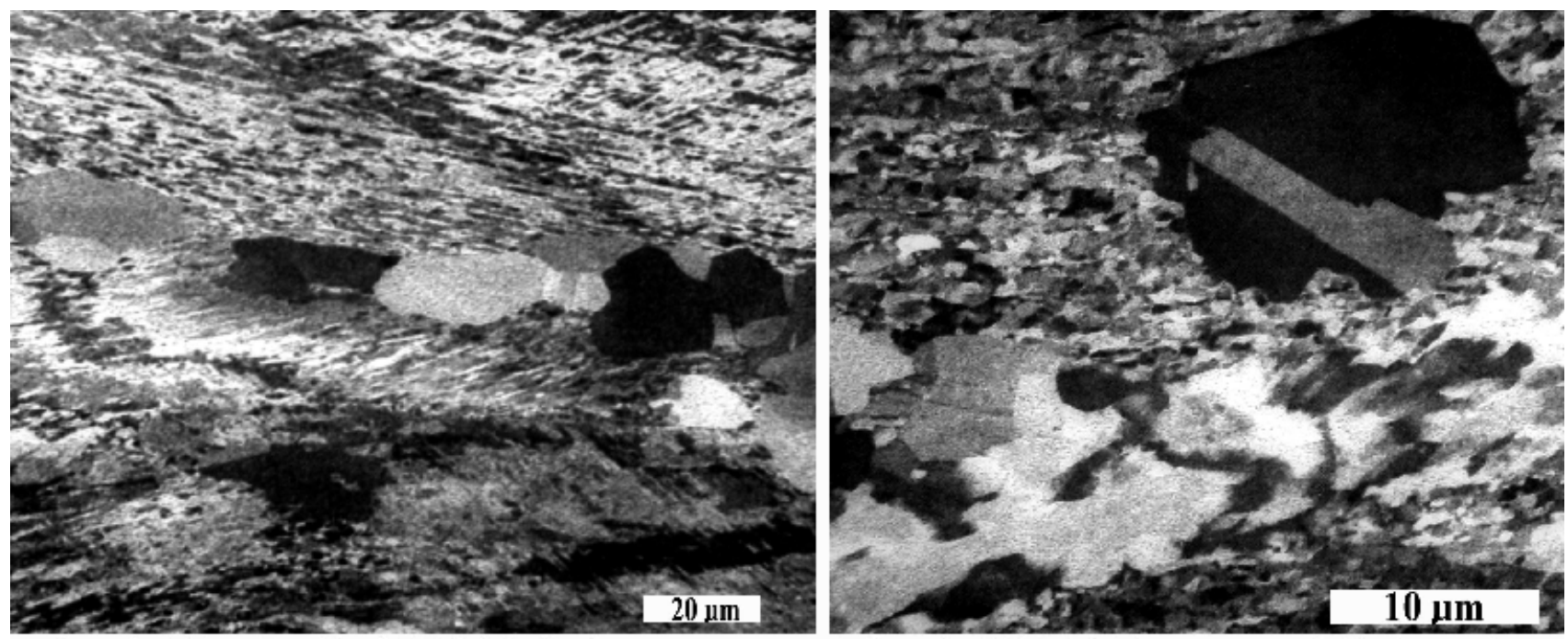

Fig. 1. Hot Rolled Ni200 Substructure.
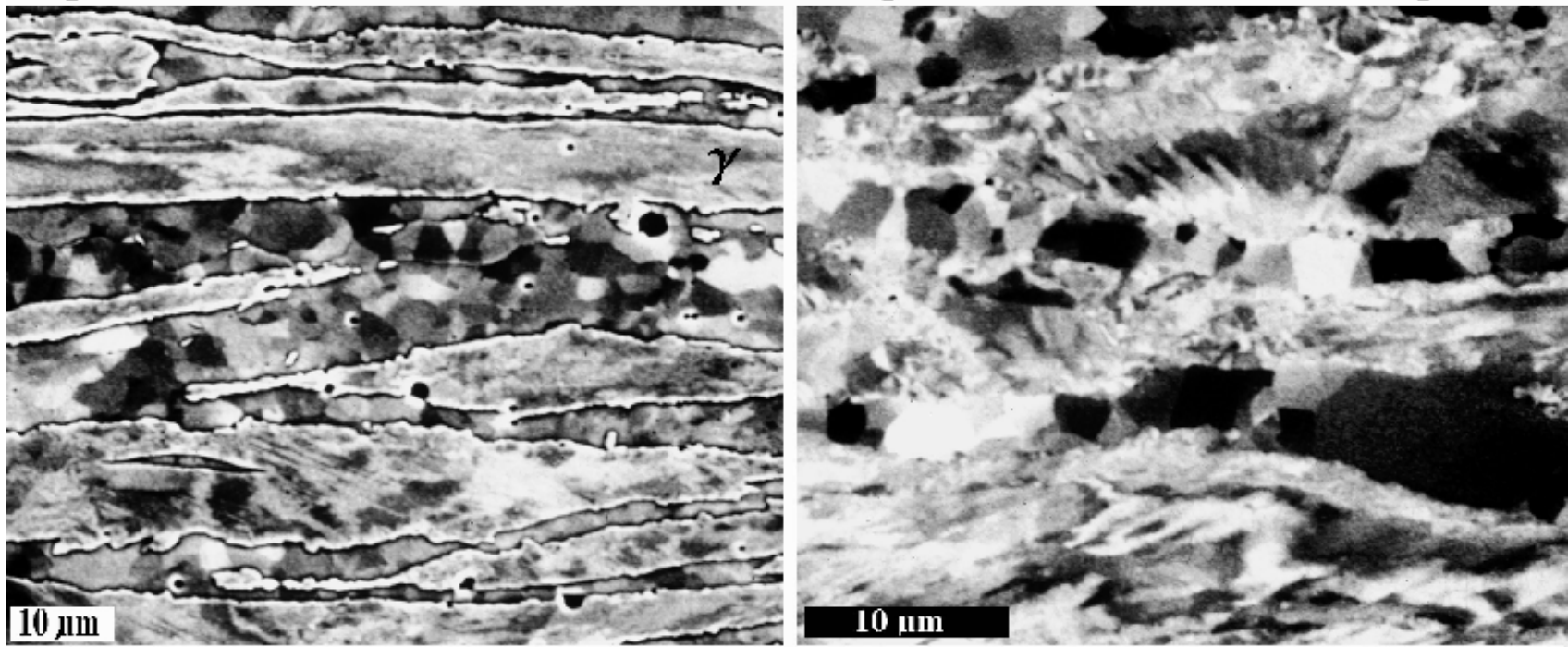

Fig. 3. Duplex Stuinless Steel-Hot Rolled.

Fig. 4. Duplex Stainless Steel-Electropolished.

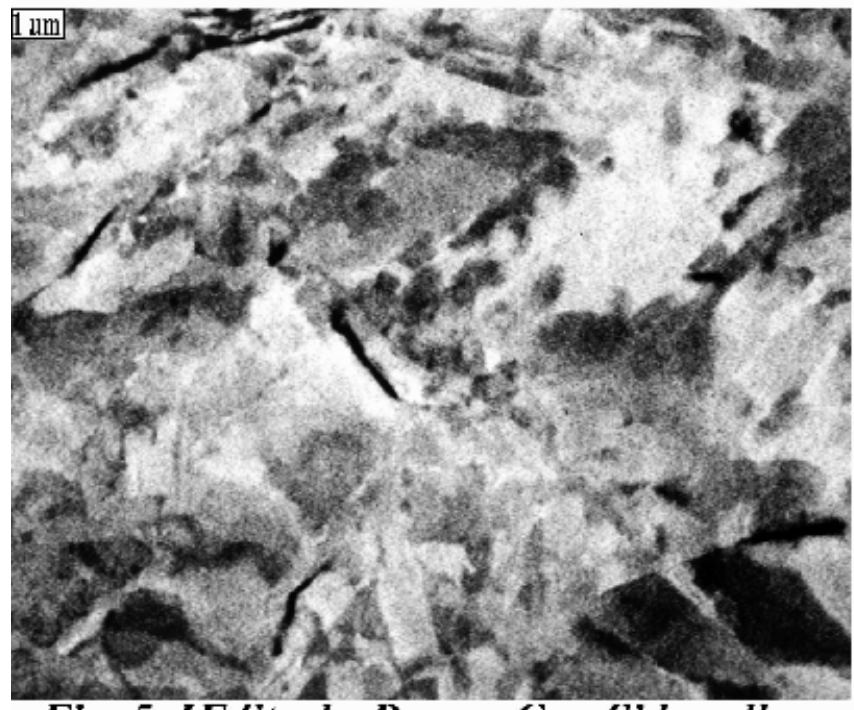

Fig. 5. IF Steel - Drawn Cup Sidewall.

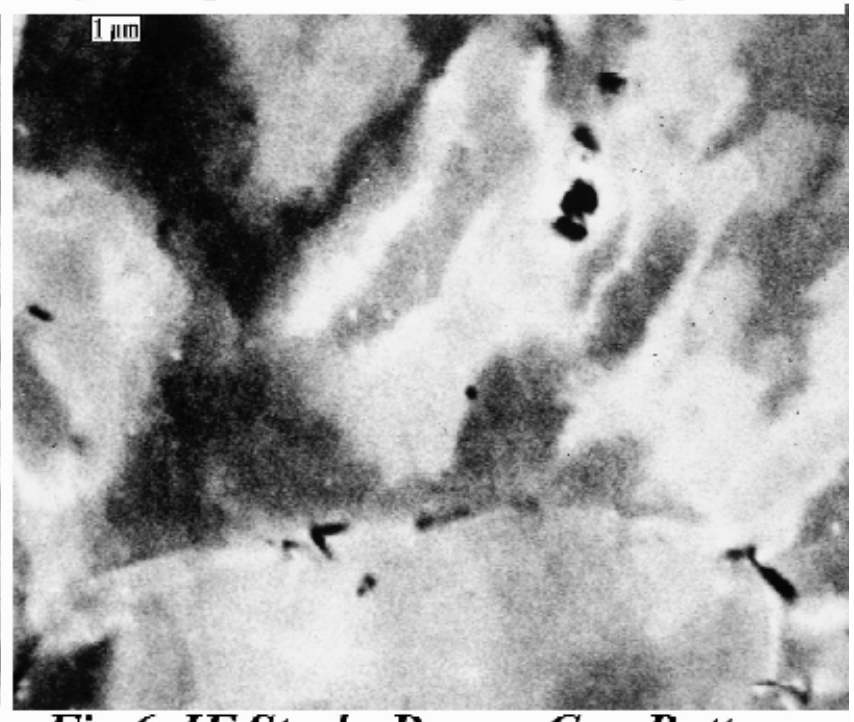

Fig.6. IF Steel - Drawn Cup Bottom. 